\title{
Fake Journals: Their Features and Some Viable Ways to Distinguishing Them
}

\author{
Mohammad Hemmat Esfe • Somchai Wongwises • \\ Amin Asadi • Mohammad Akbari
}

Received: 16 June 2014 / Accepted: 10 September 2014/Published online: 18 September 2014

(C) Springer Science+Business Media Dordrecht 2014

\begin{abstract}
In this paper, we aim to discuss the fake journals and their advertisement and publication techniques. These types of journals mostly start and continue their activities by using the name of some indexed journals and establishing fake websites. The fake journals and publishers, while asking the authors for a significant amount of money for publishing their papers, have no peer-review process, publish the papers without any revision on the fake sites, and put the scientific reputation and prestige of the researchers in jeopardy. In the rest of the paper, we present some viable techniques in order for researchers and students to identify these journals.
\end{abstract}

Keywords Fake journal $\cdot$ Publication techniques $\cdot$ Open access $\cdot$ Ethic

\section{Introduction}

For many years, researchers and students in various scientific disciplines in the world have turned the results of their researches into invaluable contexts in order to

M. Hemmat Esfe

Faculty of Mechanical Engineering, Semnan University, Semnan, Iran

S. Wongwises

Fluid Mechanics, Thermal Engineering and Multiphase Flow Research Lab. (FUTURE),

Department of Mechanical Engineering, Faculty of Engineering, King Mongkut's University of Technology Thonburi, Bangmod, Bangkok 10140, Thailand

\section{A. Asadi}

Department of Mechanical Engineering, Science and Research Branch, Islamic Azad University, Semnan, Iran 
publish them in scientific journals. The sheer existence and diversity of these types of journals in different disciplines show the broad range of the papers sent in by researchers.

In the late 1980s and early 1990s, as the access to electronic and online facilities expanded, the digital and online publications emerged. Thus, many publishers introduced their papers in the form of digital and electronic versions, which are easily accessible for researchers on the Internet. Electronic publications have no printing fees and have various other benefits. By 2011, about eleven percent of the world's articles were published in fully open-access journals (Van Noorden 2013).

In this way, the open access journals were created. The open access journals are those that use methods of publishing that include no charge for the readers who want to copy, search, print, and send articles to others (Bailey and 2005).

Therefore, in this type of journal, presenting the papers to the reader is free of charge and the expenses of publication, design, and other expenses are supplied from alternative sources.

The prime sources of supplying the expenses of these journals are:

1. Asking the researchers for the expenses (Suber 2006)

2. Receiving subsidy from some supportive organizations

3. Organizational subsidies

4. Making money based on the excessive services (Suber 2006; Bailey and 2006)

Based on the aforementioned factors, the prime source of most of these journals is the money that is received from the authors of the papers in order to publish them. This special technique, which supplies the expenses of the open access journals, leads to the creation of a type of journal that charge a fee in order to publish the papers. Also, this technique is the basis for of the fake journals.

The fake journals can be divided into two groups:

1. The journals that have no real existence and have a website to simply abuse the researchers.

2. The fake journals that impersonate the title of a well-known journal and establish a fake website, and in this way, cheat the researchers.

\section{Features of the Fake Journals}

The fake publishers and journals, regarding the keen interest of the researchers for publishing their scientific results in recent years, are booming and flourishing day by day, and they use special techniques in order to delegitimize and cheat this field. The fake publishers or journals generally have the following features:

1. They publish the papers without any revision or peer-revision process.

2. They have weak websites with a simple submission format.

3. Generally, they have no specific scientific scope and work in a multidisciplinary way. 
4. The period between submitting and publishing the papers is very short.

5. They never mention the requested fee in order to publish the papers on their sites, and notify the authors privately in a separate letter.

6. Mainly, they attach themselves to Europe and the West.

7. Commonly, they publish repetitive papers or even papers from other journals.

8. They have a broad advertisement plan in the form of spam E-mails.

9. The names of such journals commonly contain grand adjectives e.g. world, international and global (Butler 2013).

\section{The Advertisement Techniques of the Fake Journals}

This type of journal may send many spam E-mails to a very large number of unaware Internet users and researchers. If the fake journals use the name of a wellknown journal and make up its site, then most of its advertisements include the following cases:

1. Name and its impact factor (In this type of E-mail, the impact factor of the original journal is mentioned)

2. Notifying a limited period of time between the submission and peer review process (Generally less than a month)

3. Presenting the ISSN of the original journal

4. The website's address of the fake journal

5. Notifying that the journal is a multidisciplinary one

6. The journal's address (In this field the true address of the original journal is written)

7. Journal index

Recently, many journals have been made up using this technique, and by means of these fake websites, they accept, print, and publish the researchers' articles by receiving an amount of money.

The journals that fraudulently abuse their names generally have the following terms:

1. The journal is indexed in ISI and has the impact factor $\mathrm{xxx}$

2. The journal belongs to a non-English country

3. The journal has no well-known publisher

4. The journal has no electronic print and website

By using the aforementioned terms and making up the name of the journal, imposters take action in order to establish a fake website, and by means of wide advertisements, especially spam E-mails, invite the researchers to publish their papers in such fake journals. 


\section{The Assurance of Journals' Precision}

To make sure of the journals' precision, researchers and students must pay careful attention to the following terms during the submission process:

1. Sending the paper to journals that are recommended by an expert in the field.

2. Sending the paper to the journals that have a special scope and avoid sending the papers to the multidisciplinary journals.

3. Sending the articles to the well-known publishers such as Elsevier, Springer, Taylor and Francis, etc.

4. Searching the name and the DOI of a paper, accidentally, in some well-known data base such as Science Direct, Pubmed, etc.

5. Searching the information of the journals in Thomson Reuters's website and making sure of the existence of the website and its electronic publication.

6. Confirming the uniformity of the website's address of the journal, which is mentioned in the advertisement E-mails and the address that is accessible on the well-known data bases.

\section{Conclusion}

Regarding the aforementioned factors and daily development of the fake journals, the necessity for researchers to get acquainted with such journals and their publication techniques is compulsory. On the other hand, it can be helpful for the researchers and students in different scientific disciplines to identify and take legal action in order to prevent the abuse of journals and publishers by fraudulent material. Also, all universities and scientific organizations must provide an up-todate and comprehensive list of the fake journals and publishers in order to make the researchers and students aware of such traps.

Acknowledgments The authors would like to acknowledge the Semnan University Science and Technology Park for "ADVANCE RESEARCH" courses. The second author would like to thank the Thailand Research Fund and the National Science and Technology Development Agency for the supporting.

\section{References}

Bailey, C. W. Jr. (2005). Open access bibliography: Liberating scholarly literature with e-prints and open access journals. Washington, DC: Association of Research Libraries. http://digital-scholarship.org/ oab/oab.htm.

Bailey, C. W. Jr. (2006).What is open access? http://www.digital-scholarship.org/cwb/WhatIsOA.htm.

Butler, D. (2013). The dark side of publishing. Nature, 495(7442), 433-435.

Suber, P. (2006). Open access overview: Focusing on open access to peer-reviewed research articles and their preprints. http://legacy.earlham.edu/ peters/fos/overview.htm.

Van Noorden, R. (2013). Open access: The true cost of science publishing. Nature, 495(7442), 426-429. 